\title{
Mucopolysaccharidosis Type-Il with Pathognomonic Skin Appearance: A Case with Pebbling Sign
}

\author{
(1) Ayşe Hitay İnan¹, (1) Berna Şeker Yılmaz², (1) Fatma Derya Bulut³ , (1) Sebile Kılavuz ${ }^{4}$, (1) Deniz Kor ${ }^{1}$, \\ (1) Mehmet Karakaş5, (1) Halise Neslihan Önenli Mungan¹
}

1Çukurova University Faculty of Medicine, Department of Pediatric Metabolism and Nutrition, Adana, Turkey 2 Mersin University Faculty of Medicine, Department of Pediatric Metabolism and Nutrition, Mersin, Turkey ${ }^{3}$ Adana City Training and Research Hospital, Clinic of Pediatric Metabolism and Nutrition, Adana, Turkey ${ }^{4}$ Van Training and Research Hospital, Clinic of Pediatric Metabolism and Nutrition, Van, Turkey ${ }^{5}$ Çukurova University Faculty of Medicine, Department of Dermatology and Venereal Diseases, Adana, Turkey

\section{ABSTRACT}

Mucopolysaccharidosis type-II (MPS-II) is an X-linked lysosomal storage disorder. Here, we report an 8-year-old boy with pebbling sign in the scapular region, coarse facies, claw hand, diastolic murmur, and hepatomegaly. With decreased iduronate-2-sulfatase activity and hemizygous mutation in the IDS gene, the diagnosis was MPS-II. Pebbling sign is a rare but pathognomonic sign of MPS-II.

Keywords: Mucopolysaccharidosis, Hunter disease, pebbling sign

\section{Introduction}

Mucopolysaccharidosis (MPS) is a group of progressive lysosomal storage disorders caused by mutations of the genes encoding lysosomal enzymes that have a role in the degradation of glycosaminoglycans (GAG). MPS type-II is characterized by dermatan and heparan sulfate storage in all tissues due to iduronate sulfatase (IDS) enzyme deficiency caused by IDS gene mutations (1). It was first described in two brothers by Hunter (2) in 1917. Hunter syndrome (MPS type-II) is an X-linked inherited disease, whereas all the other types of MPS are autosomal recessively inherited.
Although it is almost exclusively seen in males, there are a few rare female cases reported. Its incidence is estimated to be between 1:100,000 and 1:170,000 male births (3).

The disease is known to have severe, intermediate and mild types. The clinical findings of the severe form resemble Hurler syndrome (MPS type I-H), but corneal opacities are not seen. Life expectancy is $10-20$ years. Central nervous system involvement, progressive airway disease or cardiac disease may lead to death. The mild type of the disease may be clinically confused with Scheie syndrome (MPS type I-S). Generally neurological manifestations are not seen. 
Diagnosis is made by determining a deficiency of IDS activity and mutation analysis. Enzyme replacement therapy (ERT) is the current treatment option (3).

In all types of MPS, generally the skin has a thickened appearance and it loses its elasticity. Unlike the other types of MPS, in Hunter syndrome, a pathognomonic cutaneous lesion which is known as the pebbling sign may be seen in the scapular region in particular, but may also be seen on the arms and on the thighs. These lesions are generally 2-10 $\mathrm{mm}$ in diameter, ivory white in color, papular or nodular in structure and placed in a reticular pattern (4-6). The aim of this case report is to emphasize the importance of recognizing the pebbling sign in the differential diagnosis of skin MPS-II from other types and to initiate ERT without a delay.

\section{Case Report}

An 8-year-old boy was admitted to our hospital with the complaint of abnormal skin appearance in the scapular region which was first recognized at the age of 6 years. He had symmetric, shiny, ivory-white colored, and rough surfaced lesions on the scapulae. Although the lesions persisted, diagnosis could not be made. There was nothing remarkable in the prenatal and natal history. He had not had any previously known systemic diseases. At the age of 3 months, the patient had undergone a surgery for inguinal hernia. His parents were not consanguineous and there was no similar family history. On physical examination; his weight was $20.5 \mathrm{~kg}$ (50 ${ }^{\text {th }}$ percentile), and height was 111 $\mathrm{cm}$ ( $25^{\text {th }}$ percentile). There were mild coarse facial features (Figure 1), a pebbling sign on the back (Figure 2), joint stiffness, mild claw hands (Figure 1), a 2/6 diastolic murmur, hepatomegaly ( $3 \mathrm{~cm}$ palpable in the midclavicular line), and an umbilical hernia.

Routine hematological and biochemical examinations revealed no abnormalities. Echocardiography detected $2^{\text {nd }}$ degree aortic valve insufficiency. His ophthalmological examination and hearing test were completely normal. Multisystemic involvement together with the pebbling sign led us to the diagnosis of MPS-II. Elevated amounts of urinary total GAG $[243.5 \mathrm{mg} / \mathrm{mol}$ creatinine $(\mathrm{N}:<80)]$, more specifically increased urinary dermatan and heparan sulfate, with a low plasma iduronate-2-sulfatase level $[0,0 \mathrm{nmol} /$ $\mathrm{mL} / 4 \mathrm{~h}(\mathrm{~N}: 494-1113)$ ] and hemizygous p.N63D (c.187A>G) mutation in the IDS gene confirmed the diagnosis of MPS type-II. The intelligence quotient of the patient was found to be within normal limits for his age. ERT was initiated at a dosage of $0.5 \mathrm{mg} / \mathrm{kg} /$ week. The patient has now been on ERT for 2 years. The pebbling sign has not disappeared, but improvements in joint and liver involvement have been observed. Informed consent, including visual use, was obtained from the patient's parents.

\section{Discussion}

Hunter syndrome is a rare lysosomal storage disease characterized with variability both in the age of disease onset and severity of clinical findings (1). The severe form of the disease begins at the age of 2-4 years with prominent systemic symptoms and signs which are accompanied by neurological involvement and developmental delay. These patients are generally lost in the $1^{\text {st }}$ or $2^{\text {nd }}$ decade of life because of heart failure, obstructive airway disease or neurological complications. In the milder form of the disease, clinical signs and symptoms are not prominent

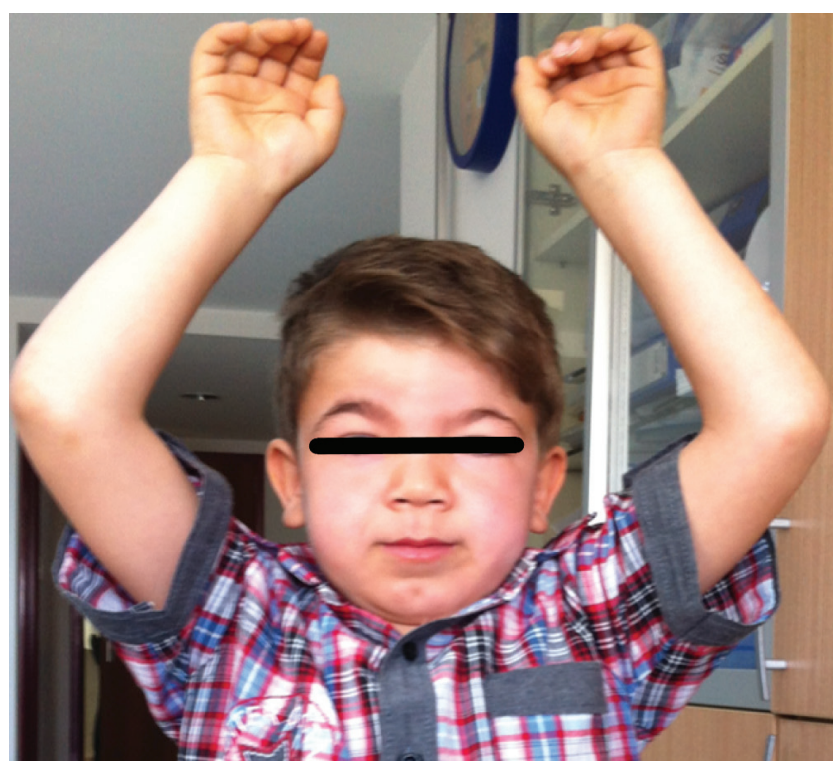

Figure 1. Coarse facial features, claw hands and joint stiffness

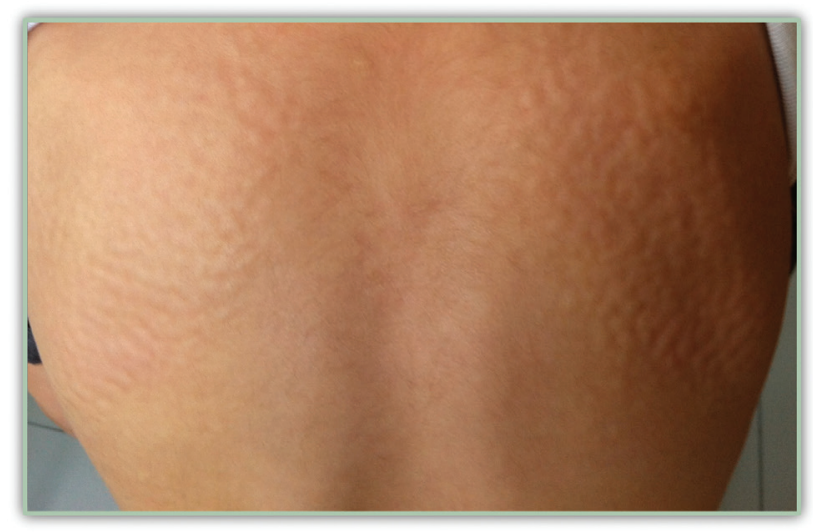

Figure 2. The pebbling sign: Papular lesions seen in a reticular pattern in the bilateral scapular region 
enough to put forward a specific diagnosis. Patients usually have normal mentality and survive into their forties or fifties. Coarse facial features with thick lips and macroglossia, macrocephaly, hypertrophic adenoids and tonsils, hearing loss, hepatosplenomegaly, umbilical and inguinal hernias, heart valve insufficiency, joint stiffness, and contractures are the common and frequently seen features of all subgroups of MPS II patients (3). However, very little is known about the definitive incidence and the impact on the prognosis of cutaneous lesions known as pebbling sign (4-7). From a report of 11 MPS type-II patients aged between 18 months and 31 years, typical skin lesions were only seen in 2 of them (5). These skin lesions often create a reticular appearance, are colored ivory-white, and sometimes consist of papules and nodules. They may be seen symmetrically in the scapula, neck, and the posterior axillary, and pectoral regions. They may also be on the upper extremities and the sides of the thighs (3). The pebbling sign is reported to appear before the age of 10 years and spontaneously recover (4-8). While other systemic findings of our patient ameliorated during the 2-year follow-up period up to the age of 10, the pebbling sign had not disappeared to date. He is the only patient with pebbling sign out of 18 MPS type-Il patients followed up in our clinic.

We report this case as the pebbling sign is a rare but an alarming feature for the diagnosis of Hunter disease that requires the early initiation of ERT before the development of other undesirable systemic manifestations.

\section{Ethics}

Informed Consent: Informed consent, including visual use, was obtained from the patient's parents.

Peer-review: Externally peer-reviewed.

\section{Authorship Contributions}

Concept: A.H.I., B.Ş.Y., F.D.B., Design: S.K., D.K., M.K., H.N.Ö.M., Data Collection or Processing: A.H.I., B.Ş.Y., F.D.B., S.K., D.K., Literature Review: S.K., D.K., Editing Assistance: M.K., H.N.Ö.M., Writing: A.H.İ., B.Ş.Y., F.D.B.

Conflict of Interest: No conflict of interest was declared by the authors.

Financial Disclosure: The authors declared that this study received no financial support.

\section{References}

1. Jones S, Wijburg F. Mucopolysaccharidoses. In: Saudubray JM, Baumgartner MR, Walter I (eds). Inborn Metabolic Diseases Diagnosis and Treatment, 6th ed. Berlin, Springer, 2016;577-84.

2. Hunter C. A rare disease in two brothers. Proc R Soc Med 1917; 10:104-16.

3. Martin R, Beck M, Eng C. Recognition and diagnosis of mucopolysaccharidosis ii (hunter syndrome). Pediatrics 2008; 121:e377-86. doi: 10.1542/peds.2007-1350.

4. Cole HN, Irving RC, Lund HZ, et al: Gargoylism with cutaneous manifestations. Arch Dermatol 1952; 66:371-83.

5. Prystowsky SD, Maumenee $\mathrm{IH}$, Freeman RG, Herndon $\mathrm{JH} \mathrm{Jr}$, Harrod MJ. A cutaneous marker in the Hunter syndrome-a report of four cases. Arch Dermatol 1977; 113:602-5.

6. Maize J, Metcalf J. Metabolic diseases of the skin. In: Elder $D_{\text {, }}$ Elenitsas R, Jaworsky C, Johnson B Jr (eds). Lever's histopathology of the skin, 8th ed. Philadelphia, Lippincott-Raven, 1997;392-3.

7. Freeman RG. A pathological basis for the cutaneous papules of mucopolysaccharidosis II (The Hunter syndrome). I Cutan Pathol 1977; 4:318-20.

8. Thappa DM, Singh A, laisankar T), Rao R, Ratnakar C. Pebbling of the skin: a marker of Hunter's syndrome. Pediatr Dermatol 1998; 15:370-3. 